Technological University Dublin ARROW@TU Dublin

2005-01-01

\title{
Electronic Speckle Pattern Shearing Interferometry for Nondestructive Testing of Thermal Sprayed Alloy Coatings
}

\author{
Yueqiang Xue \\ Technological University Dublin \\ David Kennedy \\ Technological University Dublin, david.kennedy@tudublin.ie \\ Emilia Mihaylova \\ Technological University Dublin, emilia.mihaylova@tudublin.ie
}

Follow this and additional works at: https://arrow.tudublin.ie/cieocon2

Part of the Optics Commons

\section{Recommended Citation}

Yueqiang X, Kennedy, D. \&Mihaylova, E. (2005) Electronic Speckle Pattern Shearing Interferometry for Nondestructive Testing of Thermal Sprayed Alloy Coatings. Proceedings of SPIE: OPTO-IRELAND 5824, 241. doi:10.1117/12.605034 doi.org/10.21427/ks1h-6g27

This Conference Paper is brought to you for free and open access by the Centre for Industrial and Engineering Optics at ARROW@TU Dublin. It has been accepted for inclusion in Conference Papers by an authorized administrator of ARROW@TU Dublin. For more information, please contact arrow.admin@tudublin.ie, aisling.coyne@tudublin.ie,gerard.connolly@tudublin.ie.

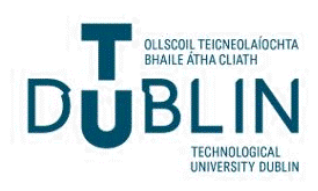


2005-01-01

\section{Electronic Speckle Pattern Shearing Interferometry for Nondestructive Testing of Thermal Sprayed Alloy Coatings}

Yueqiang Xue

Dublin Institute of Technology

David Kennedy

Dublin Institute of Technology, david.kennedy@dit.ie

Emilia Mihaylova

Dublin Institute of Technology, emilia.mihaylova@dit.ie

\section{Recommended Citation}

Yueqiang X, Kennedy, D., Mihaylova, E.: Electronic Speckle Pattern Shearing Interferometry for Nondestructive Testing of Thermal Sprayed Alloy Coatings. Proceedings of SPIE: OPTO-IRELAND 5824, 241 (2005); doi:10.1117/12.605034

This Conference Paper is brought to you for free and open access by the Centre for Industrial and Engineering Optics at ARROW@DIT. It has been accepted for inclusion in Articles by an authorized administrator of ARROW@DIT. For more information, please contact

yvonne.desmond@dit.ie, arrow.admin@dit.ie. 


\title{
Electronic Speckle Pattern Shearing Interferometry for Nondestructive Testing of Thermal Sprayed Alloy Coatings
}

\author{
Yueqiang Xue* $^{\star}$ David Kennedy*, Emilia Mihaylova** \\ *Faculty of Engineering, \\ Dublin Institute of Technology, Bolton Street, Dublin 1, Ireland \\ Qiang.Xue@dit.ie \\ ** Centre for Industrial and Engineering Optics, \\ Dublin Institute of Technology, Kevin Street, Dublin 8, Ireland
}

\begin{abstract}
Thermal sprayed coatings have wide engineering applications. There now exists a wide range of destructive and nondestructive testing (NDT) methods for surface coating inspections. This paper describes an application of Electronic Speckle Pattern Shearing Interferometry (ESPSI) for NDT of thermal sprayed surface coatings. In contrast to other conventional methods such as eddy current, ultrasonic or X-ray, ESPSI allows fast and large survey area inspection. Experimental results of shearographic measurements are presented. Thermal sprayed coatings were tested using ESPSI. Delaminations of the coatings were detected and the fringe patterns were captured using this method. It is shown that the shearography technique can be applied successfully to surface coating quality inspection and it is very effective for delamination detection.
\end{abstract}

Keywords: Coatings; Nondestructive testing; Electronic Speckle Pattern Shearing Interferometry 


\section{INTRODUCTION}

Thermal spraying is regarded as one of the key enabling surface engineering technologies. Since the thermal spraying technique was invented in the early part of the twentieth century, the use of thermal sprayed coatings has grown enormously and they are extensively used across the whole spectrum of engineering industries. In the thermal spraying processes, the consumable coating materials are fed to the spray gun and the temperature is raised, and then the materials are projected in a particulate form to strike the workpiece forming a coating of desired thickness. Thermal spraying techniques include flame spraying, arc spraying, plasma spraying, High Velocity Oxyfuel spraying (HVOF) and detonation flame spraying ${ }^{1}$.

The principle of thermal spraying is that the coating materials are deposited on the substrate surface of a component to form a layer with a different material composition. Thus the combination of the coating and the substrate might be considered as a composite structure. Composite structure normally has a high possibility of having flaws due to the rules of formation and processing methods. It is important to have an access to NDT techniques to evaluate the structural integrity of the reinforced layer and the component substrate. Consequently, there is a need of inspection for surface coating to assess its deposition quality, to ensure its performance during the service life. Optical methods such as holography, Electronic Speckle Pattern Interferometry (ESPI), Electronic Speckle Pattern Shearing Interferometry (ESPSI), moiré techniques and thermography are emerging as strong candidates for industrial inspections. ESPSI also called shearography has been developed during the last two decades and it was proved to be a very useful and powerful tool in non-destructive evaluation of structures and materials ${ }^{2}$. Shearography has been accepted by the rubber industry for non-destructive evaluation of tyres ${ }^{3}$. Also, it has increasing applications in automotive and aerospace industries in the field of NDT of composite materials ${ }^{4}$. Compared with ESPI, shearography has great advantages of revealing defects in materials by finding strain anomalies which are induced by delaminations. Also unlike ESPI, shearography depicts defects differently, as shown in Figure 1. This is because ESPI can only directly measure displacement while ESPSI enables direct measurements of displacement derivatives to be made.
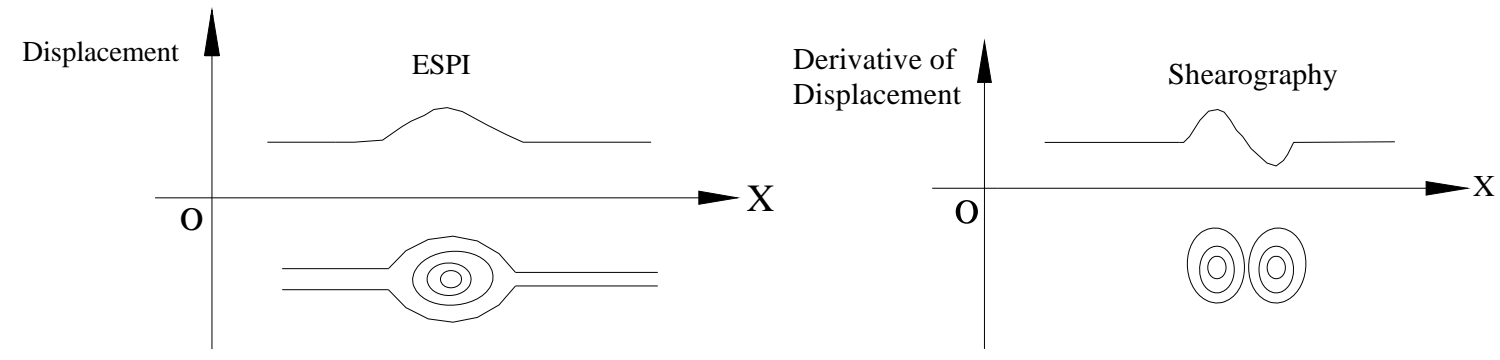

Figure 1. Schematic representation of ESPI and Shearography measurements of a defect

\section{THEORY}

In ESPSI one laser beam is used to illuminate the surface of the object under test and an image-shearing device is employed to form two overlapped speckle images of the object on the image plane of a CCD video camera ${ }^{5}$. These two speckled images interfere with each other to generate a speckle pattern. When the object has been deformed or displaced, the resultant speckle pattern changes. The second resultant speckle pattern is transferred to the computer and subtracted from the stored pattern and the result rectified. The resulting interferogram is displayed on the monitor as a pattern of dark and bright fringes. In real time it is possible to grab frames continuously while a deformation is occurring and then subtract them in succession from the first speckle pattern. This process makes it possible to observe the real-time formation and the progressive changes of the fringe pattern related to the deformation of the surface. Electronic Speckle Pattern Shearing Interferometry enables direct measurements of displacement derivatives to be made with variable sensitivity. 
When two light waves interfere, the following equation ${ }^{6}$ relates their relative phase $\phi$ at a location to their relative geometrical path length $L$.

$$
\phi=\frac{2 \pi}{\lambda} n L-\beta
$$

Where $\lambda$ is the wavelength of the laser light, $n$ is the refractive index of the media through which the laser light is transmitted, and $\beta$ is a constant phase. The change in the relative phase $\Delta=\delta \phi$ or phase change, which manifests as visible fringes, can be effected by an incremental change in any one of the three parameters $\lambda, n$, and $L$. Thus,

$$
\Delta=\frac{\partial \phi}{\partial \lambda} \delta \lambda+\frac{\partial \phi}{\partial n} \delta n+\frac{\partial \phi}{\partial L} \delta L=-\frac{2 \pi L n}{\lambda^{2}} \delta \lambda+\frac{2 \pi L}{\lambda} \delta n+\frac{2 \pi n}{\lambda} \delta L
$$

Where $\delta \lambda, \delta$ and $\delta L$ respectively denote to the incremental change in wavelength, in refractive index, and in relative geometrical path length of the interfering waves.

If the same wavelength is used and the test environment is still air $(n=1)$, only the $\delta L$ term in Eq. (2) is nonzero, resulting in the following equation for phase change:

$\Delta=\frac{2 \pi}{\lambda}(A \delta u+B \delta v+C \delta w)$

Where $u, v$, and $w$ are the displacement components of the neighboring point $Q(x+\Delta x, y, z+\Delta z)$ relative to point $P$ (x, y, z) on the test surface; and $A, B$, and $C$ are sensitivity factors that are related to the optical arrangement.

For small image shearing $\delta x$, the displacement terms in Eq. (3) can be expressed in terms of partial derivatives:

$\Delta=\frac{2 \pi}{\lambda}\left(A \frac{\partial u}{\partial x}+B \frac{\partial v}{\partial x}+C \frac{\partial w}{\partial x}\right) \delta x$

In the experiment (Figure 4), it is assumed that the illuminating beam is perfectly collimated, and it only lies in the $x-Z$ plane. Therefore, there is no sensitivity to the displacement along y axis. In this case, Eq. (4) can be simplified as:

$\Delta=\frac{2 \pi}{\lambda}\left(A \frac{\partial u}{\partial x}+C \frac{\partial w}{\partial x}\right) \delta x$

\section{EXPERIMENTAL INVESTIGATION}

\subsection{Thermal spraying coating process}

Two thermal sprayed coating samples were prepared in Dublin Institute of Technology by using the Castolin's Superjet Eutalloy spray gun. The steps in the Superjet Eutalloy process are surface preparation, pre-heating, spraying and fusing process. The process of thermal sprayed coating deposition is shown in Figure 2. 


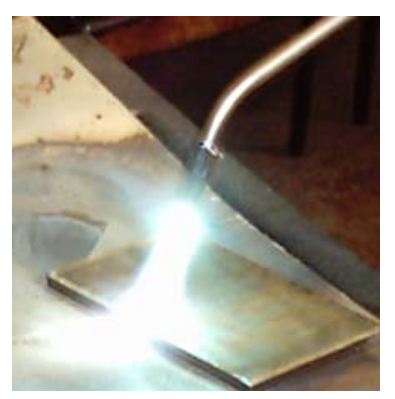

(a)

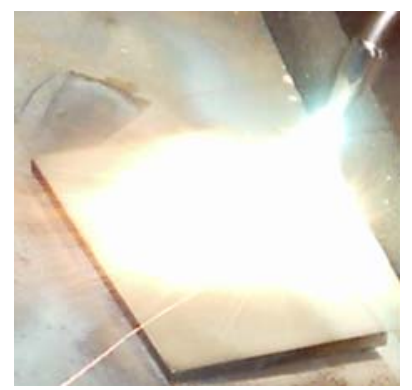

(b)

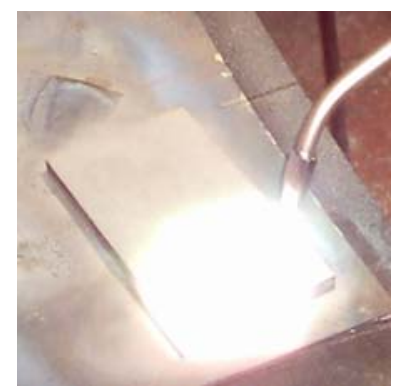

(c)

Figure 2. Thermal spraying coating process: (a) Pre-heating; (b) Spraying; (c) Fusing

The finish and integrity of the substrate surface are crucial for the application of thermal sprayed coatings. In this experiment, samples were carefully prepared and the cleaning of the substrate surfaces was carried out by sand blasting, which is a process of removing the rust, grease, oxides and impurities from the surface using a jet of sand. Preheating was carried out by igniting the gun and heating the substrate with the gun flame up to $150^{\circ} \mathrm{C}$ approximately. This is to take the chill out of the base metal and prevent the hot powder from contracting and lifting off.

\begin{tabular}{ll} 
Parameters & Values \\
\hline Distance of spraying $(\mathrm{mm})$ & $25 \sim 30$ \\
Distance of fusing $(\mathrm{mm})$ & $6 \sim 20$ \\
Temperature of fusing $\left({ }^{\circ} \mathrm{C}\right)$ & 1100 \\
Oxygen Pressure (bar) & 2 \\
Acetylene Pressure (bar) & 0.5 \\
\hline
\end{tabular}

Table 1. Spray parameters recommended by Castolin Eutectic for Superjet Eutalloy Process

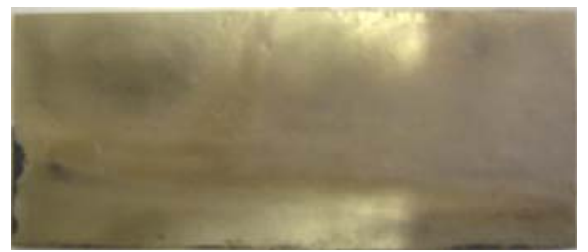

Figure 3. Picture of a coated sample

In the Superjet spraying process, oxygen flows through the injector which then draws the powder into the system by aspiration. At the same time, the acetylene gas is carried separately until it reaches the mixer assembly. At this point both gases are mixed and the powders are carried through the system until they reach the spray tip and enter into the flame. After the spraying, a wet-out process, which is called fusing, was carried out in succession. The fusing process was to promote the bonding between the coating and the base metal, and also to eliminate the oxide formed during spraying. Table 1 outlines the standard spraying parameters for the Superjet Eutalloy process, which is recommended by Castolin Eutectic Group ${ }^{7}$. Figure 3 shows the sample coated with NiBSi based alloy powder. Table 2 introduces the alloy powders, which were used for the coating process. 10112 and 10185 are the company product numbers. 


\begin{tabular}{lllll} 
Powders & $\mathrm{Si}+\mathrm{B}$ & $\mathrm{Cr}$ & $\mathrm{Ni}$ & Comments \\
\hline $\begin{array}{l}10112 \\
\text { (TungTec) }\end{array}$ & 5 & 5 & Balance & $\begin{array}{l}\text { 60\% WC particle weight, excellent } \\
\text { resistance to erosion and abrasion }\end{array}$ \\
\hline $\begin{array}{l}\text { 10185 } \\
\text { (BronzoChrom) }\end{array}$ & 6 & 0.5 & Balance & $\begin{array}{l}\text { Highly resistant to corrosion and } \\
\text { impact stress }\end{array}$ \\
\hline
\end{tabular}

Table 2. Descriptions of the coating powder materials used in the experiment

\subsection{Optical setup}

The optical setup ${ }^{8}$ used for the ESPSI testing is shown in Figure 4. A He-Ne laser with wavelength of $633 \mathrm{~nm}$ and maximum power of $20 \mathrm{~mW}$ is used as the light source in the experiment. The test object is illuminated by the laser beam at an angle to the normal of the object surface. The two images of the tested object are formed by reflection from the shearing device and they are imaged by a CCD camera.

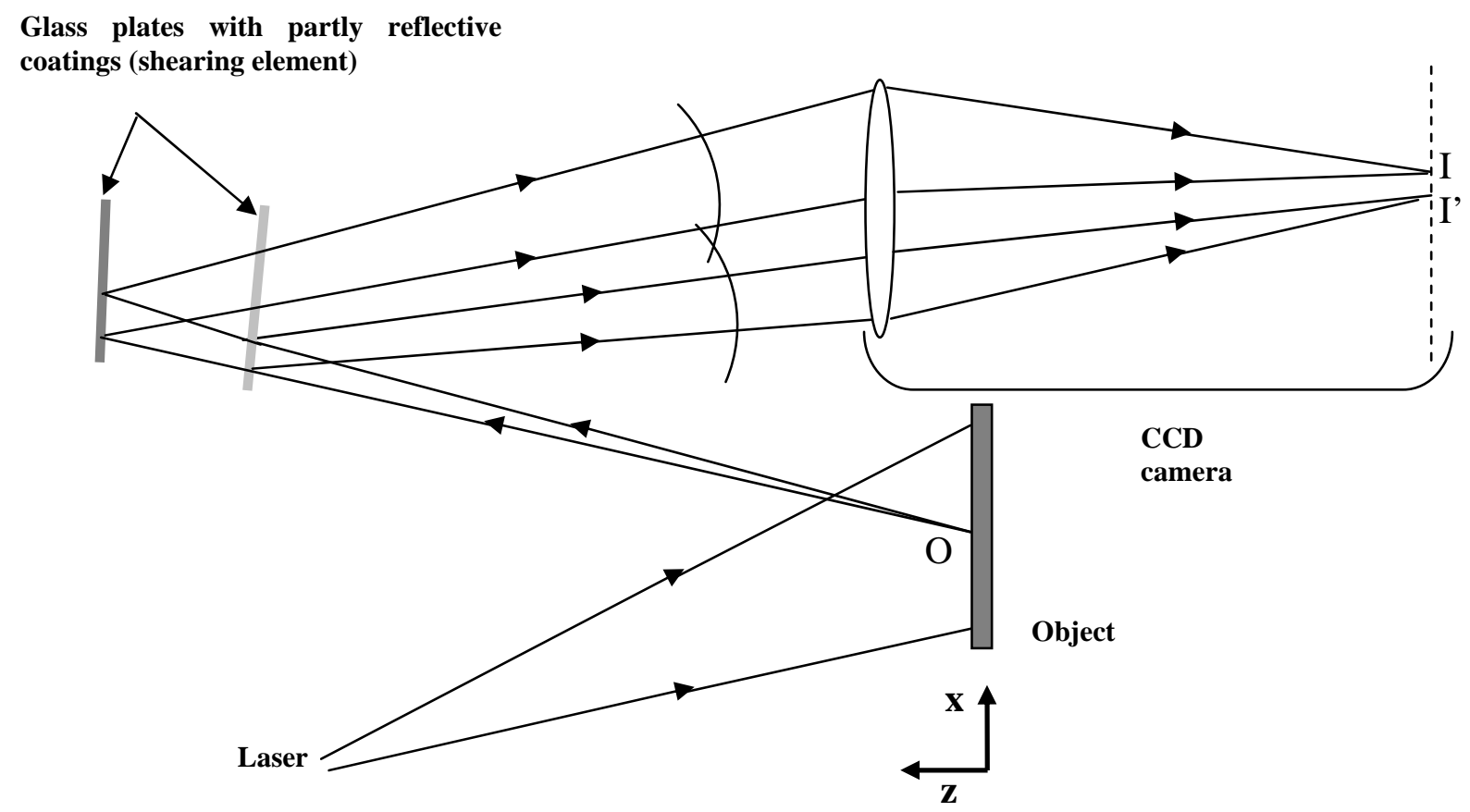

Figure 4. Schematic arrangement of the ESPSI

The shearing device used in this system consists of two glass plates (Figure 4) with reflection coefficients of the coatings 0.3 and 0.7 respectively ${ }^{8}$. One of the mirrors is slightly tilted to produce a lateral shear. The resultant speckle patterns are produced by digital subtraction of the speckled images of the object before and after deformation.

In order to detect the presence of the surface coating defects, a localised displacement field was induced. Various stressing methods can be used depending on the type of material and the defects being investigated, as described by Hung $^{3}$. In this experiment, two stressing methods were employed - three-point bending and thermal stressing. Previously designed and constructed three-point bending test rig for deformation of metal samples in the sub-micrometer range ${ }^{9}$ was used for mechanical stressing. This test rig (Figure 5) satisfied the requirement of controlling the bending deformation on 
the coated sample surface precisely (up to $20 \mathrm{~nm}$ ) for shearography. The purpose of the arrangement is to compare the changes in shearographic fringe patterns on the sample surface with predetermined displacements. The thermal stressing method was used in the investigation also and it was carried out by using a tungsten-halogen lamp. The field of view is $30 \mathrm{~mm} \times 20 \mathrm{~mm}$ in all experiments (Figure 6). It was assumed here that the lateral shearing is in $x$ direction only, and there will be no shearing in the $y$ direction.

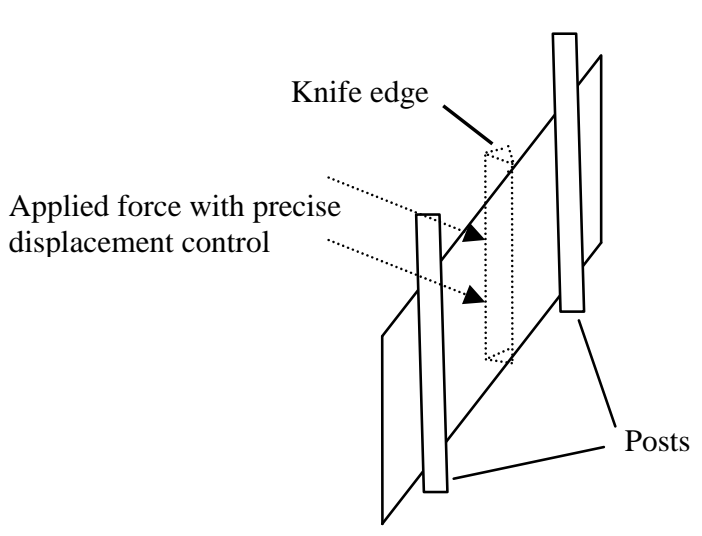

Figure 5. A scheme of three-point bending test rig

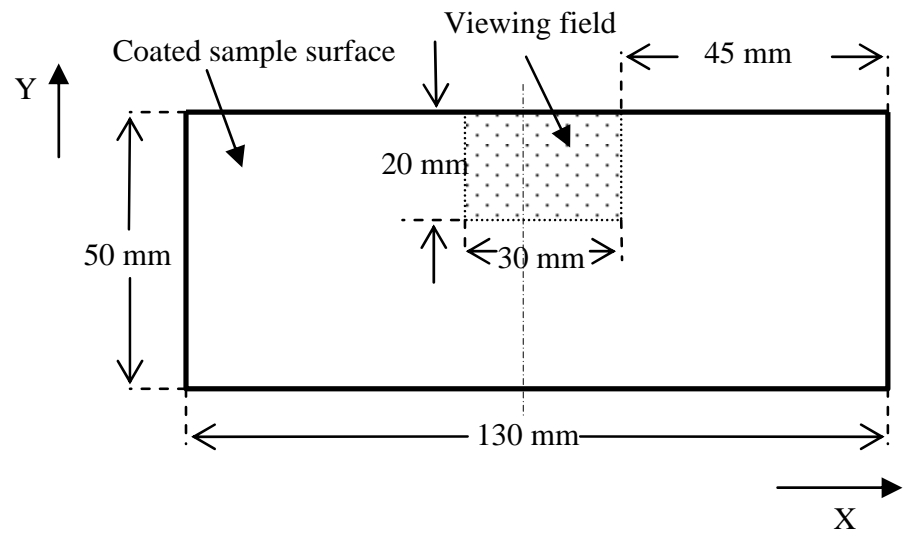

Figure 6. Viewing area on the coated sample

\section{RESULTS AND DISCUSSION}

Figure 7 shows the area under investigation on the sample 10112. Figure 8 shows the shearographic fringe patterns depicting the derivatives of the deflections on sample 10112. These fringe patterns are obtained in real time. Respectively, Figure 8 (a), (b), (c) and (d) represent deflections of 40nm, 80nm, 120nm and 160nm produced by the three-point bending test rig. It is observed that these fringe patterns have a very good repeatability and consistency, which proves that this three-point bending test rig produces the required displacements and is suitable for ESPSI quantitive measurement.

Figure 9 presents some examples of the ESPSI results for non-defective sample 10112 under cooling. The sample was stressed by heating it with a tungsten-halogen lamp. During experiments we observed irregular dark fringes moving rapidly all over the area under investigation. They disappear quickly, and there is no repeatability and consistency. They are clearly due only to the random variations in the rate at which the surface cools and contracts.

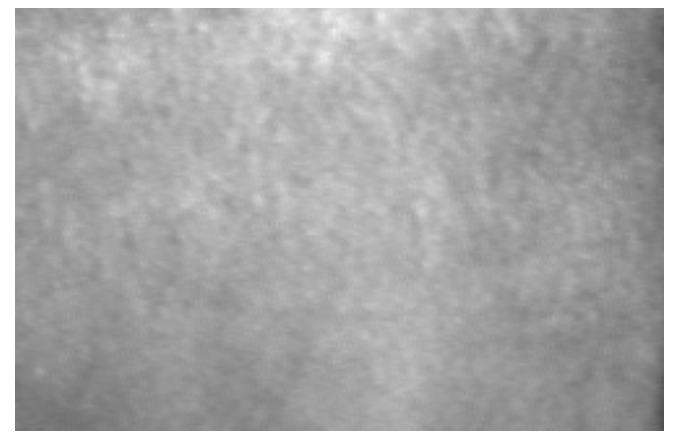

Figure 7. The area of the sample 10112 under investigation. The field of view is $30 \mathrm{~mm} \times 20 \mathrm{~mm}$. 


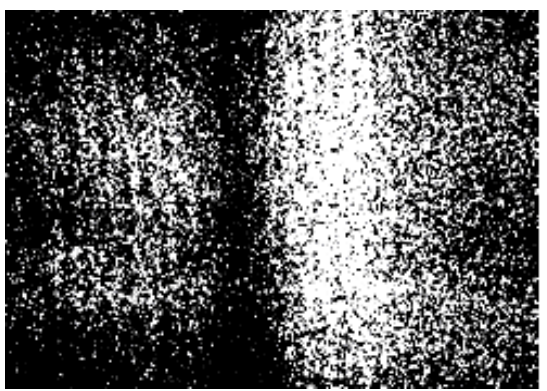

(a)

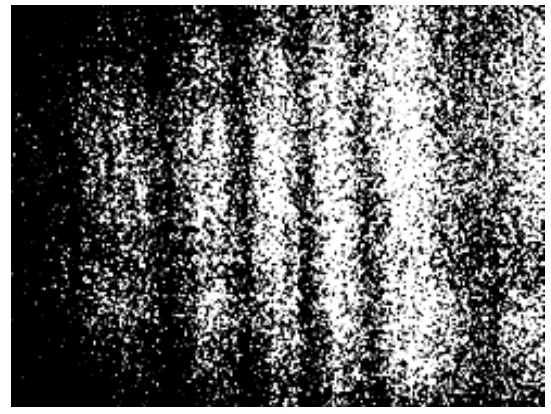

(c)

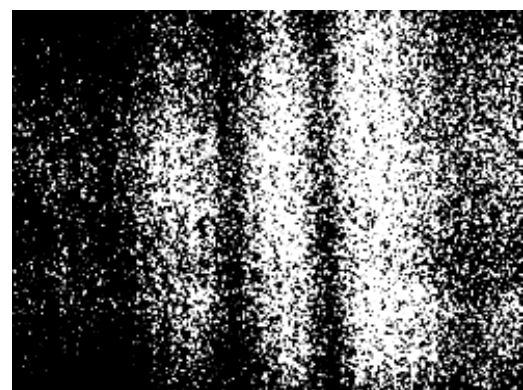

(b)

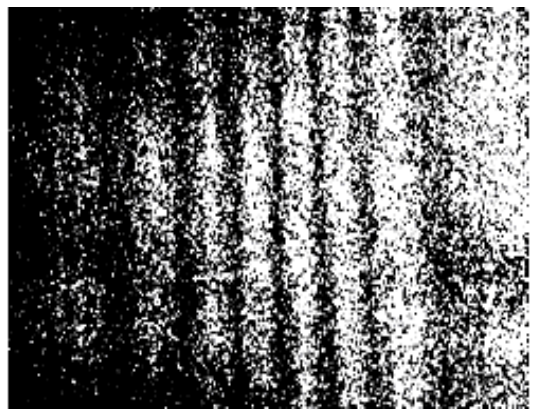

(d)

Figure 8. ESPSI fringe patterns of coated sample 10112 during three-point bending under deflection of: (a) $40 \mathrm{~nm}$; (b) $80 \mathrm{~nm}$; (c) $120 \mathrm{~nm}$; (d) $160 \mathrm{~nm}$. The shear is $\Delta x=8 \mathrm{~mm}$. The field of view is $30 \mathrm{~mm} \times 20 \mathrm{~mm}$.

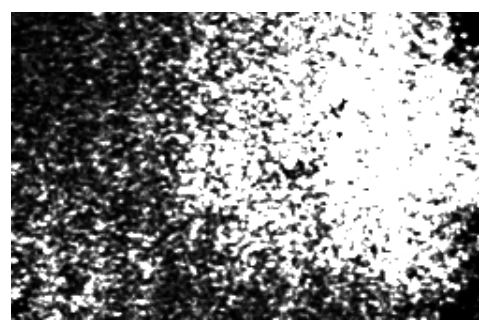

(a)

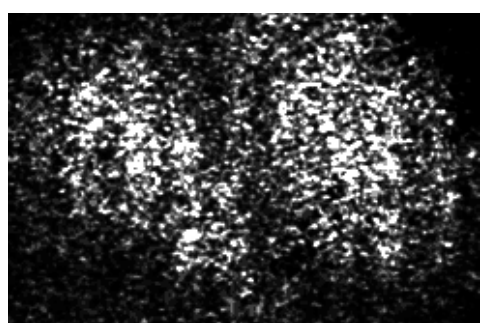

(b)

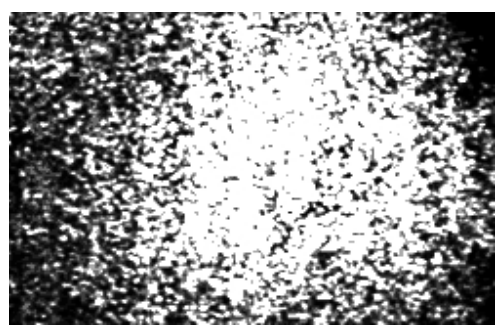

(c)

Figure 9. ESPSI fringe patterns of coated sample 10112 under thermal stressing by using a tungstenhalogen lamp during cooling: (a) $2^{\text {nd }}$ second; (b) $4^{\text {th }}$ second; (c) $6^{\text {th }}$ second. The shear is $\Delta x=8 \mathrm{~mm}$. The field of view is $30 \mathrm{~mm} \times 20 \mathrm{~mm}$.

On sample 10185, a large delamination on the coating was found, as shown in Figure 10. In this area, a part of the coating was lifted off due to the poor coating adhesion. Figure 11 shows the ESPSI results for the sample 10185 which obtained at the $1^{\text {st }}, 2^{\text {nd }}, 3^{\text {rd }}$ and $4^{\text {th }}$ second of the recording. In this case, the sample was thermally loaded by using a tungsten-halogen lamp illuminating near the sample surface for approximately 30 seconds. This time, in addition to the rapidly moving fringes observed above, fringes were consistently observed in the area of the delamination. This is probably due to the very different cooling rate there, and indicates the presence of large disbond at the suspect area in the sample 10185. 


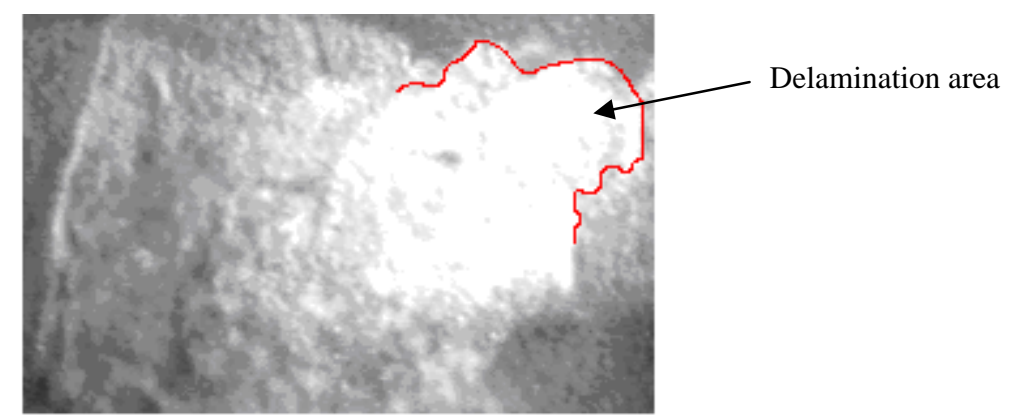

Figure 10. Delamination area of the sample 10185 The field of view is $30 \mathrm{~mm} \times 20 \mathrm{~mm}$

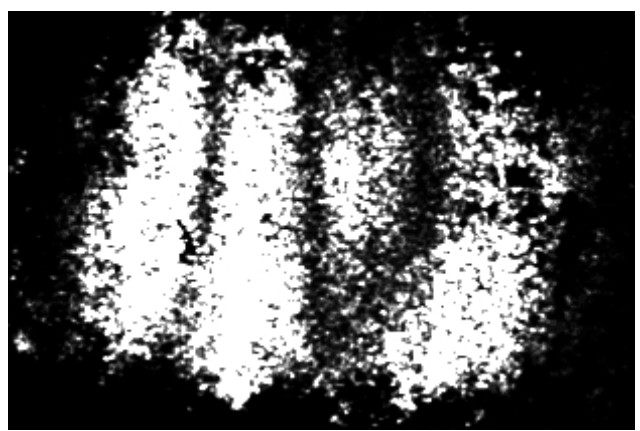

(a)

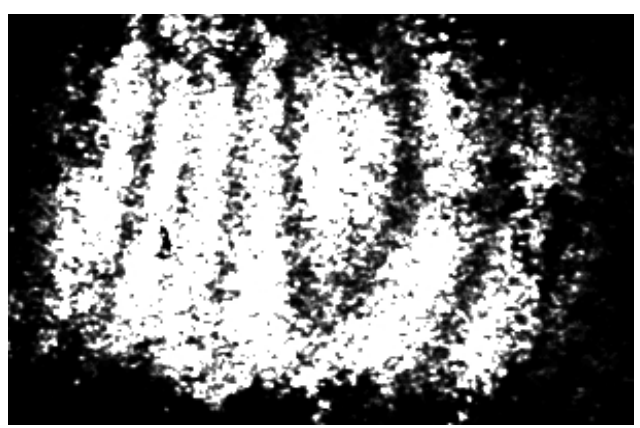

(c)

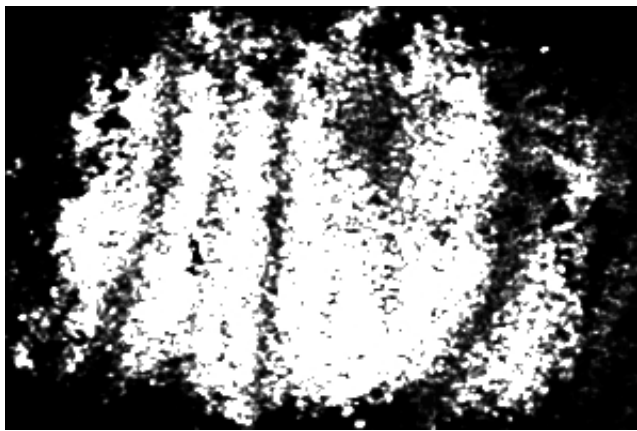

(b)

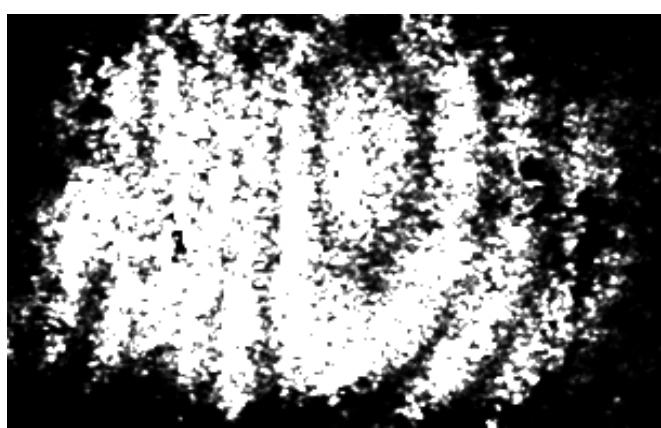

(d)

Figure 11. ESPSI fringes of coated sample 10185 under thermal stressing by using a tungsten-halogen lamp during cooling: (a) $1^{\text {st }}$ second; (b) $2^{\text {nd }}$ second; (c) $3^{\text {rd }}$ second; (d) $4^{\text {th }}$ second. The shear is $\Delta x=10 \mathrm{~mm}$. The field of view is $30 \mathrm{~mm} \times 20 \mathrm{~mm}$.

Figure 12 shows the ESPSI results for the sample 10185, which were obtained under mechanical stressing. ESPSI fringes were repeatably produced and consistently observed in the area of the delamination. 

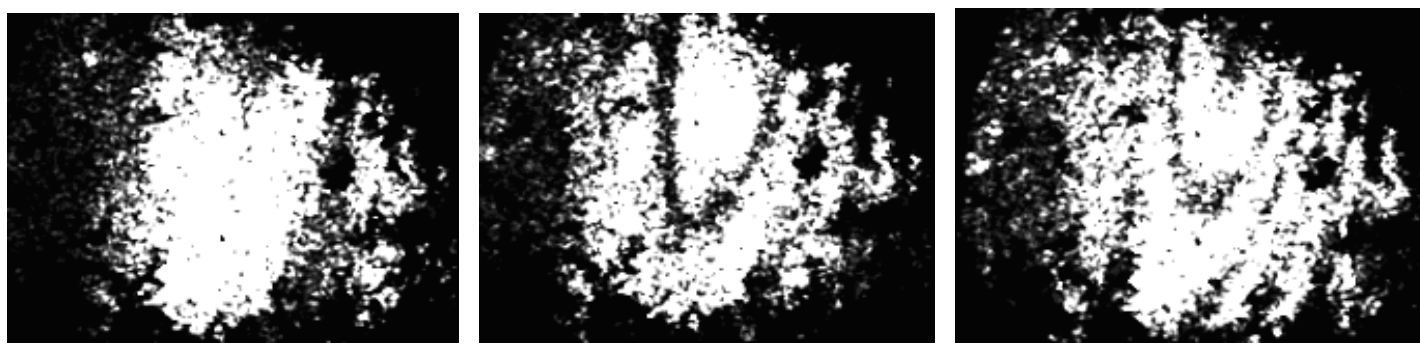

Figure 12. ESPSI fringes of coated sample 10185 under mechanical stressing by using a three-point bending test rig under deflection of: (a) $20 \mathrm{~nm}$; (b) $40 \mathrm{~nm}$; (c) $60 \mathrm{~nm}$. The shear is $\Delta x=10 \mathrm{~mm}$. The field of view is $30 \mathrm{~mm} \times 20 \mathrm{~mm}$.

\section{CONCLUSIONS}

The results show that ESPSI is suitable for detection of delaminations and disbonds in thermal sprayed alloy coatings. The type and the magnitude of the loading affect the success of defect detection significantly. Thermal stressing and mechanical stressing are both suitable as loading methods for detection of delaminations in metal coatings.

Shearography would seem to have great potential for NDT and quality inspection of thermal sprayed alloy coatings, based on its advantages: simple optical set-up, easy to detect defects which create strain concentrations, fast full-field technique, insensitive to small rigid body motions and thus suited for industrial applications.

\section{ACKNOWLEDGEMENTS}

The authors would like to thank to Dr. Vincent Toal and Dr. Suzanne Martin for the valuable discussions. Emilia Mihaylova would like to thank the Arnold F. Graves Postdoctoral programme at Dublin Institute of Technology.

\section{REFERENCES}

1. Frainger, S., Blunt, J., Engineering Coatings - Design and Application, $2^{\text {nd }}$ edition, Abington Publishing, England, 1998.

2. Hung, Y. Y., "Shearography: a novel and practical approach for nondestructive testing". J. Nondestructive Testing, 8(2) 55-67, 1989.

3. Hung, Y. Y., "Shearography for non-destructive evaluation of composite structures". Opt. Lasers Eng. 24, 161-182, 1996.

4. Yang, L. X., Hung, Y. Y., "Digital shearography for nondestructive evaluation and application in automotive and aerospace industries". Proceedings of $16^{\text {th }}$ World Conference on NDT, Montreal, 2004.

5. Chen, F., "Digital shearography: state of the art and some applications", Journal of Electronic Imaging. 10 (1), 240251, January 2001.

6. Vest, C. M., Holographic Interferometry, John Wiley \& Sons, New York, 1979.

7. Information Documents and Technical Specifications, Castolin Eutectic Company Ltd.

8. Mihaylova, E. M., Whelan, M. P., Toal, V., “A simple phase-shifting lateral shearing interferometer”, Optics Letters. 29 (11), 1264, June 2004.

9. Mihaylova, E., Murphy, N., Xue, Y., Kennedy, D., Toal, V., “Test rig design for optical inspection of metal samples by electronic speckle pattern shearing interferometry”. Proceedings of MATRIB’04, p. 33, Vela Luka, 2004. 